considerably, to the extent that 40 seconds of $8 \cdot 2 \mathrm{gz}$ was an exhilarating experience marred only by central anginal chest pain due to sternal pressure: any roller coaster will forever be a tame comparison.

Not so gx however, where the upright posture encourages massive distal pooling and at the final run at 5 gx I rapidly "greyed" then "blacked out," before lapsing into sleep. I awoke feeling extraordinarily tranquil, seemingly hours but in reality only seconds later, with a doctor grinning down at me. The intervening period was blurred by bizarre but not unpleasant memories of complex dreams concerning dogs, mingled with nagging sensations of confusion. The video evidence explained my curious calmness on waking - a hypoxic tonic-clonic fit. I completed my other tests of prolonged altitude simulation and motion sickness satisfactorily, but knew my centrifugal performance was a major setback.

Thus ended my involvement with Juno, in combination with an unacceptable degree of myopia and a history of hay fever. Soviet medical review excluded me and numerous other candidates for various seemingly minor problems. I cannot deny a tinge of envy at those who, having become friends, will continue along the path. I feel a certain self satisfaction, and privilege, to have met a group of fascinating people, one of whom will make history. Although no experience was necessary, much has been gained.

\title{
Hospital formularies: need for continuous intervention
}

\author{
John Feely, Robert Chan, Lelia Cocoman, Kenneth Mulpeter, Patricia O'Connor
}

\begin{abstract}
The effects of introducing a hospital formulary alone and with active intervention were compared prospectively with regard to drug costs and the quality of prescribing. Intervention comprised feedback on prescribing habits, peer comparison, and information on drugs. Aspects of prescribing that were not subjected to intervention did not alter. In the year in which intervention occurred generic prescribing rose by $50 \%$; inappropriate prescribing and overall use of third generation cephalosporins fell; and compliance with the recommended list of drugs was good. Overall, drug costs remained static, compared with a projected increase of $10.25 \mathrm{~m}$; in a comparative control hospital drug costs rose by $18 \%$. During the next year, when no form of intervention took place, previous gains were eroded and drug costs rose.
\end{abstract}

Continuous intervention, review, and feedback are required if a formulary is to continue to achieve its objectives.

\section{Introduction}

Hospital formularies are now widely accepted,' and there is evidence that a restricted drugs policy can initially reduce costs. ${ }^{1-4}$ As there is little information on the effect of a formulary on the quality of prescribing ${ }^{45}$ or the need for continuous intervention we undertook a study in which certain aspects of the formulary and prescribing were selectively subjected to feedback for a defined period and others were not. Drug use was monitored over three years.

\section{Department of}

Pharmacology and

Therapeutics, Trinity

College Medical School, St

James's Hospital, Dublin 8,

Ireland

John Feely, MD, professor

Robert Chan, $\mathrm{MB}$, medical

intern

Lelia Cocoman, BSC,

pharmacist

Kenneth Mulpeter, MRCPI, registrar

Patricia O'Connor, MRCPI, registrar

Correspondence to:

Professor Feely.

\section{Methods}

This hospital is an 800 bed general hospital with expanding services whose drug bill rose by about $20 \%$ a year in the 1980 s to $£ 1.7 \mathrm{~m}$ in 1985 . As there is no Irish national formulary our list of recommended drugs was drawn up after a survey of the drugs actually used, reference to experience with the Dundee formulary, ${ }^{3}$ and information from the coordinating centre for drugs and therapeutics committees in Southampton. ${ }^{6}$ The formulary contained 330 drugs covering all categories, and a preliminary description has been published elsewhere. The aim was to improve prescribing practice by encouraging prescription of drugs on the grounds of efficacy, safety, and economy. Four hundred prescriptions were collected from representative general medical and surgical units on two occasions before the formulary was introduced. Subsequent surveys were made one, four, and 12 months after its introduction; during this year intervention took place.' The final survey was made at the end of a further 12 months during which no intervention occurred. That these samples were representative of overall hospital prescribing was confirmed by two separate surveys of over 4500 prescriptions.

Specific forms of intervention included feedback of prescribing habits to individual prescribers and consultants in charge of units. In addition, peer comparisons and examples of specific savings were provided to prescribers. A drug information note was prepared in conjunction with the hospital's clinical microbiologists on the use and abuse of third generation cephalosporins. In addition, prescribing habits were discussed at the monthly medical committee meetings. Only selected aspects of prescribing were, however, subjected to intervention. Special attention was paid to generic prescribing and the use of third generation cephalosporins. General guidelines on prescribing were contained within the formulary, but otherwise no specific form of intervention was made with regard to using clear instructions, giving dates for the start and end of treatment, using capital letters, and recording drug allergies on prescription charts. When a prescriber wished to obtain a drug not included in the formulary a separate requisition was completed, and these were reviewed on a monthly basis.

We used Dr Steevens's Hospital, with 220 beds, as a concurrent control as it adopted an identical formulary without any form of intervention.

\section{Results}

Generic prescribing-The amount of generic prescribing in the hospital rose progressively by almost $50 \%$ in the year after introduction of the formulary, in both the medical and surgical units (from $50 \%$ to $72 \%$ and $38 \%$ to $62 \%$ respectively). In the subsequent year without feedback generic prescribing reverted to its former level (table I).

Prescribing practice-Aspects of prescribing practice that were not subjected to feedback did not change.

Requisition of drugs not in formulary-Once prescribers became familiar with the formulary requisitions for drugs not in it constituted $5 \%$ of all prescriptions and were mostly for analgesics (dextropropoxyphene), compound antibiotics, cephalosporins, theophylline preparations, diuretics, and 
TABLE I-Number of prescriptions for generic drugs in samples of 400 prescriptions looked at before formulary was introduced, when it was used with feedback, and when it was used alone subsequently

\begin{tabular}{lccccc}
\hline & \multirow{2}{*}{\begin{tabular}{c} 
Before \\
\cline { 3 - 5 }
\end{tabular}} & \multicolumn{3}{c}{ Formulary used with feedback } & Formulary used alone \\
\cline { 3 - 6 } & formulary introduced & At 1 month & At 4 months & At 12 months & $\begin{array}{c}\text { (at 24 months) } \\
\text { Medical units }\end{array}$ \\
Surgical units & 200 & 232 & 276 & 304 & 200 \\
& 152 & 176 & 204 & 248 & 160 \\
\hline
\end{tabular}

TABLE II-Influence of feedback on number of requisitions per month for drugs not in formulary in two consecutive months before and eight non-consecutive months during feedback and six non-consecutive months consecutive months before and
sampled in last year of study

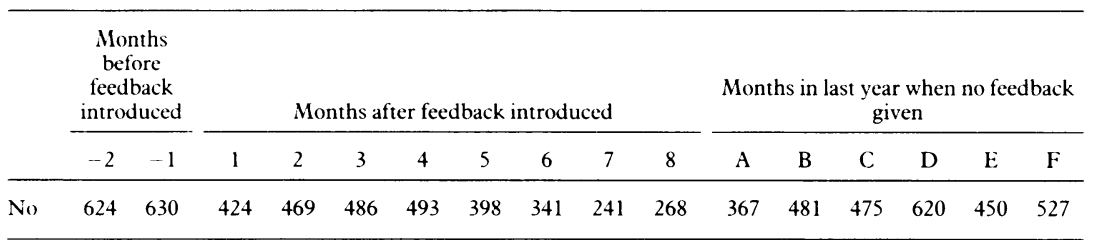

TABLE III - Sample survey of use of cefotaxime

\begin{tabular}{|c|c|c|c|}
\hline & \multirow{2}{*}{$\begin{array}{c}\text { Before } \\
\text { formulary used } \\
(n=35)\end{array}$} & \multicolumn{2}{|c|}{ Formulary in use } \\
\hline & & $\begin{array}{l}\text { With intervention } \\
\qquad(\mathrm{n}=39)\end{array}$ & $\begin{array}{l}\text { Without intervention } \\
\qquad(\mathrm{n}=35)\end{array}$ \\
\hline Prescribed as drug of first choice & 24 & 14 & 25 \\
\hline Appropriate microbiological assessment done & 15 & 33 & 21 \\
\hline Annual cost to hospital (£) & 112000 & 75000 & 94000 \\
\hline
\end{tabular}

hypnotics. After intensive feedback the number was reduced by about one third but rose again until further feedback, when it fell to $2 \%$ (table II). During the subsequent year when no intervention took place the proportion of requisitions remained static at about $5 \%$ of all monthly prescriptions.

Use of third generation cephalosporins-Before the formulary was introduced the use of cefotaxime, which accounted for over $95 \%$ of third generation cephalosporins prescribed, was unsatisfactory; most patients received it as a drug of first choice, commonly in the absence of microbiological assessment (samples or sensitivity testing). After intervention both the quality and quantity of its prescribing improved (table III). The $29 \%$ reduction in annual use was associated with a larger reduction in the annual cost $(33 \%)$ because of a $15 \%$ fall in the retail price of this drug during the period of study. In the subsequent year without intervention its use increased again as did expenditure despite a further $20 \%$ reduction in cost. Furthermore, the quality of prescribing also deteriorated (table III). There was an additional $£ 10000$ spent on other third generation cephalosporins.

Financial aspects - In the year after the formulary was introduced clinical activity increased slightly while the cost of drugs per occupied bed day (£6.60) was unaltered. Consequently drug costs fell slightly, by $£ 1$ per patient. In the comparative hospital with no intervention drug costs rose by $18 \%$. Subsequently that hospital was partly closed with the loss of general medical and surgical services. During the third year of the study (without intervention) inpatient activity at $\mathrm{St}$ James's Hospital fell slightly (by $3 \cdot 2 \%$ ). In addition, retail drug costs (based on the average price of the top 10 items during the year) fell by $5 \%$ owing to a revised price agreement between the Department of Health and the Federation of Irish Che snical Industries and an advantageous exchange rate between the Irish punt and sterling. Despite these favourable changes drug costs rose by about $6 \%$ (figure).

\section{Discussion}

Although hospital formularies are now widely accepted, the impact has been critically evaluated in only a few instances..$^{2 \cdot 9}$ Despite the stated primary objective of improving drug use $\mathrm{e}^{101 !}$ analysis has concentrated on the purported secondary aim, which is to reduce drug costs. ${ }^{11}$ Most studies, ${ }^{2-4}$ but not all," have reported an initial reduction in drug costs. There are obvious difficulties in designing a study that entails withdrawing a formulary or using a comparative hospital as a control given the current rapid changes in health services. Nevertheless, we believe that our findings are valid and representative of actual practice in many hospitals.

In common with other authors ${ }^{2-4}$ we found a reduction in projected expenditure on drugs of about $15 \%$ during the initial year. This is in line with the figure estimated by the American Society of Hospital Pharmacists. ${ }^{13}$ We also found that with appropriate feedback the quality of prescribing, as exemplified by the use of generic names (table I) and the third generation cephalosporin cefotaxime (table III), improved. Cefotaxime became less commonly used as the antibiotic of first choice and in the absence of microbiological data. We also noted that items not subjected to feedback showed no change. There was a suggestion that the rate of change-for example, decline in use of drugs that were not in the formulary was rapid and proportional to the amount of feedback.

Our data showed that in the absence of feedback previous gains may be lost: generic prescribing fell to the level seen before the formulary was used (table I) clinical use of cefotaxime without microbiological assessment increased (table I), and adherence to the recommended list as evidenced by the use of requisitions for drugs not in the formulary fell (table II). In addition, the annual drug costs started to rise again (figure) despite a reduction in retail drug costs and hospital activity.

Possibly enthusiasm for hospital formularies waned after their initial success; fewer than half the drugs and therapeutics committees in the United Kingdom now operate a formulary. ${ }^{11}$ There is also evidence that some of the original committees, including the national coordinating centre, have disbanded ${ }^{14}$ or abandoned their formularies. ${ }^{11}$ Petrie and Scott suggested recently that the efficiency and resources needed to maintain a formulary are not now considered a priority ${ }^{11}$; this concurs with our experience. Our results suggest that initial gains after a formulary is set up may be quickly lost and that continuous feedback and intervention are required if a formulary is to continue to achieve its objectives of improving drug use and reducing costs.

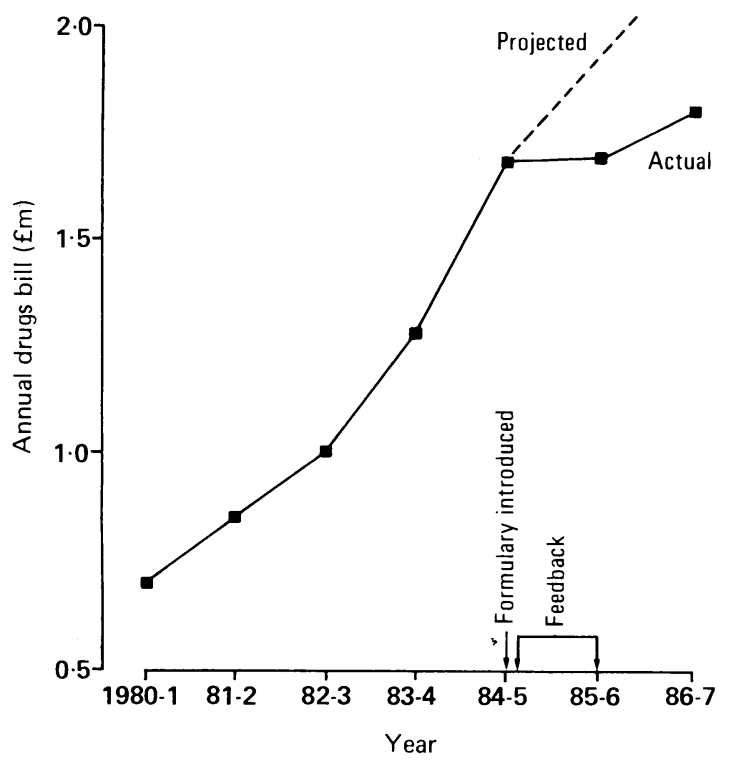

Annual expenditure on drugs before and after introduction of formulary 
1 Turner P. Local formularies and good patient care. $B r$ Med 7 1984:288:348. Collier J, Foster J. Management of a restricted drugs policy in hospital: the firs five years' experience. Lancet 1985; $1: 331-3$.

3 Crooks J. Drug epidemiology and clinical pharmacology: their contribution to patient care. Br f Clin Pharmacol 1983;16:351-7.

4 Baker JA, Lant AF, Sutters C. Seventeen years' experience of a voluntar based drug rationalisation programme in hospital. Br Med $\mathcal{J}$ 1988;297. $465-9$

5 Anonymous. Local drug formularies-are they worth the effort? Drug Ther Bull 1989;27:13-6.

6 George $\mathrm{CF}$, Hands DE. Drugs and therapeutics committees and information pharmacy service: the United Kingdom. World Dev 1983;ii:229-36.

Feely J, Chan R, Cocoman L. Impact of a hospital formulary on prescribing habits and drug costs. Ir Med f 1987;80:286-7.

8 Swallow RD, Remington HStC, Standing VF. Ward pharmacy: a positive contribution to cost control. Pharmaceutical fournal 1985;235:722-3.
9 Plumridge RJ, Stoelwinder JU, Barbatis CG. Improving patient care and pharmacy management: the effect of hospital formularies. Drug Intell Clin Pharm 1984:18:652-6.

10 Anonymous. Local formularies - the way ahead [Editorial]. Lancet 1986;ii 1078-9.

11 Petrie JC, Scott AK. Drug formularies in hospitals. Br Med $\mathcal{F}$ 1987;294: 919-20.

12 Green JA. The formulary system and the emperor's new clothes. Am $\mathcal{F}$ Hosp Pharm 1986;43:2830-4.

13 Anonymous. American Society of Hospital Pharmacists technical assistance bulletin on hospital formularies. Am f Hosp Pharm 1985;42:375-7.

14 Ferrano MC, Henman MC. A survey of drug and therapeutic committees operating in Ireland. Journal of Clinical and Hospital Pharmacy 1986;ii: $131-40$.

(Accepted 29 September 1989)

\section{How To Do It}

\section{Write a classic paper}

\author{
Anthony David
}

Most of this occasional series has dealt with negotiating those minor hurdles placed in the way of the busy clinician going about his or her routine. This article is about the big one-writing a classic paper. A classic paper is that elusive blend of art and science, a piece of scholarship that changes the way people think but also delights each new readership that rediscovers it. Words like elegant and lucid are the adjectives most often used to describe one. This is not to be confused with a citation classic, which need not be worthy of such accolades. These are often technical articles describing a laboratory technique (such as gas-liquid chromatography) or a rating scale (such as the general health questionnaire), or they may contain statements designed to be tendentious and annoying, stirring up colleagues to write refutations (more or less anything by Eysenck). No, classic papers are different. For one thing they tend to happen by accident. But here are a few guidelines to follow so maybe one of us will get lucky.

\section{Getting in the mood}

First of all you have to make a major finding or conduct a substantial study. This article assumes you have done that already. If you haven't, don't stop reading you may get some ideas. After all they have to start somewhere. Next are some practical hints. Get yourself a word processor. No one ever wrote a classic paper in one sitting, believe me. Some word processors can check your prose and cut out words like inasmuch and moreover, which you never find in a really important work of science. You should allow yourself to get into a writing mood. Finish the background reading, the review of the literature, and the work to date. You know it inside out. Relax. Take deep breaths. Just let it flow. Many people find music a help but choose carefully. Something light and formal not intrusive or demanding. Mozart obviously. A lot of people like Simon and Garfunkel. Avoid the romantics and counterpoint. Fugues make demands on the left hemisphere and could effectively muzzle your writing ability. Steer clear of anything Italian, especially opera. Jazz (such as Louis Armstrong or early Ella Fitzgerald) is alright so long as it is not too rhythmic and evocative; you'll end up tapping in time on the keyboard and this could slow you down or you may even start smoking again. Sonny Rollins is absolutely contraindicated for obvious reasons. And if you must drink coffee, stick to decaffeinated. Wear comfortable clothes; a sweater and jeans are fine.

\section{The title}

I cannot emphasise too much how important the title is. Colleagues of mine persevered with Microprocessor assisted clinical assessment and management of minor psychiatric disorders and suffered rejection from journal after journal. Someone suggested The computer will see you now and the BMF lapped it up. Titles beginning with "On" are good such as On the circulation of the blood (Harvey), On the origin of species (Darwin), and On aggression (Lorenz); they suggest the monumental, something enduring. Other titles echo through the literature. In my own subject, Sex and the single girl became Sex and the single hemisphere (Witelson) and (note the twist) Psychotherapy and the single synapse (Kandel). Another was What the frog's eye tells the frog's brain (Lettvin), which became What the mind's eye tells the mind's brain (Pylyshyn), and many others. "Towards" is a bit like "On" in that it conveys portent without bragging. For example, Towards a theory of schizophrenia (Bateson), which heralded the double bind and later, Towards an aetiological classification of schizophrenia (Murray), a less famous but quite influential work. Question marks in titles are corny, and colons are the refuge of a coward. The authors thought of a snappy title and then spoilt it by sticking in a colon followed by "pathological findings" or "a new theoretical framework" or even "physiological studies in the newt."

\section{Style matters}

Whatever you do, do not mention statistics (terms like logistic regression, factor analysis) unless you are writing about them specifically. Otherwise it is just going to alienate your audience. The same goes for code names or numbers for new drugs and the precise locus of the new gene you have just identified. Put these in parentheses or use a footnote. Some people like quotations. Be careful it doesn't come over as pretentious: French and Latin are out; anything by Shakespeare, Bertrand Russell, and Peter Medewar is safe.

What follows should not be a problem. The study itself or your new theory. Just let it come out, don't force it. Find a style that you feel comfortable with. Be a bit old fashioned, that can give the paper a sense of solidity and trustworthiness. "Notwithstanding" is perfectly acceptable in the 1990s if used sparingly, so is "with respect to." "Heretofore" is going too far and "the aforementioned" makes you sound like a lawyer. Try not to let the reader see that what you have to say is
BrMed f 1990;300:30-1

\section{London SE5 8AF \\ lecturer \\ Anthony David, MRCPSYCH,}

